\title{
Food effect on the bioavailability of two distinct formulations of megestrol acetate oral suspension
}

\author{
This article was published in the following Dove Press journal: \\ International Journal of Nanomedicine \\ I September 2009 \\ Number of times this article has been viewed
}

\section{Benoit Deschamps' \\ Naomi Musaji ${ }^{2}$ \\ John A Gillespie ${ }^{2}$}

'SFBC Anapharm, Montreal, Canada; ${ }^{2}$ Strativa Pharmaceuticals, a division of Par Pharmaceutical, Inc., Woodcliff Lake, NJ, USA
Correspondence: Naomi Musaji, PharmD Strativa, division of Par Pharmaceutical, Inc., 300 Tice Boulevard, Woodcliff Lake, NJ 07677, USA

Email naomi.musaji@strativapharma.com
Objective: Megestrol acetate oral suspension (MAOS) is an appetite stimulant indicated for cachexia in patients with AIDS. It is available in its original formulation, Megace ${ }^{\mathbb{B}}$ (MAOS), and as a nanocrystal dispersion, Megace ${ }^{\circledR}$ ES (MA-ES). Three studies were conducted to evaluate the pharmacokinetic properties of these formulations under fed and fasting conditions.

Methods: An open-label, crossover trial was conducted in 24 healthy males randomized to MA-ES $625 \mathrm{mg} / 5 \mathrm{~mL}$ given with a high-calorie, high-fat meal, or after an overnight fast. Blood samples were drawn at multiple time points and pharmacokinetic parameters were determined. Two separate, open-label reference studies evaluated MAOS $800 \mathrm{mg} / 20 \mathrm{~mL}$ in $40 \mathrm{fed}$ or 40 fasting healthy male volunteers.

Results: In fasting MA-ES subjects, the average maximum concentration $\left(\mathrm{C}_{\max }\right)$ was $30 \%$ less than the fed $\mathrm{C}_{\max }$ value. For MAOS, fasting $\mathrm{C}_{\max }$ was $86 \%$ less than fed $\mathrm{C}_{\max }$. In fasting subjects, the area under the curve was $12,095 \mathrm{ng} \cdot \mathrm{h} / \mathrm{mL}$ for MA-ES, and 8,942 $\mathrm{ng} \cdot \mathrm{h} / \mathrm{mL}$ for MAOS. In fed subjects, the absorption of the two formulations was comparable.

Conclusion: Bioavailability and absorption are greater for MA-ES than MAOS in fasting subjects. MA-ES may be a preferred formulation of megestrol acetate when managing cachectic patients whose caloric intake is reduced.

Keywords: megestrol acetate, bioavailability, cachexia, nanocrystal technology, appetite stimulant

\section{Introduction}

Nutritional status affects health, disease state outcomes, and quality of life. ${ }^{1,2}$ Inadequate food intake that does not meet metabolic and caloric demands can lead to unintended weight loss (UWL), a distinguishing clinical feature of cachexia. ${ }^{3}$ Cachexia or wasting disease is associated with underlying illness such as AIDS, cancer, heart failure, kidney failure, COPD, or rheumatoid arthritis, ${ }^{4}$ and is distinct from conditions such as starvation, malabsorption, age-related loss of muscle mass, or hyperparathyroidism. ${ }^{3}$ As many as 5 million people in the United States, or $20 \%$ to $40 \%$ of those affected with chronic conditions, may require treatment for cachexia. ${ }^{4}$ Among patients with AIDS, cachexia is a prevalent comorbidity, affecting up to $35 \%$ of AIDS patients in the United States. ${ }^{4}$ Diagnostic criteria for cachexia include UWL $\geq 5 \%$ in 12 months or less in the presence of underlying illness or body mass index (BMI) $<20 \mathrm{~kg} / \mathrm{m}^{2}$; additional criteria are described by Evans et al 2008. ${ }^{3}$

Megestrol acetate oral suspension (MAOS) is an orexigenic agent indicated for the treatment of anorexia, cachexia, or an unexplained, significant weight loss in patients with AIDS. The original formulation of MAOS (Megace ${ }^{\circledR}$; Bristol-Myers 
Squibb, Princeton, New Jersey, USA) is relatively more viscous than other liquid medications and the recommended dose of $800 \mathrm{mg} / 20 \mathrm{~mL}$ or 4 teaspoons, ${ }^{5}$ once daily may be limiting factors for patients with decreased appetite or difficulty swallowing. To improve the palatability of MAOS, nanocrystal technology (Elan Pharma International Limited, King of Prussia, Pennsylvania, USA) was applied to produce a nanocrystal dispersion ${ }^{6}$ of megestrol acetate (MA-ES; Megace ${ }^{\circledR}$ ES; Par Pharmaceutical, Inc., Spring Valley, New York, USA), which is a more concentrated suspension with improved dissolution and decreased viscosity.

An initial pharmacokinetic (PK) study demonstrated that MA-ES $625 \mathrm{mg} / 5 \mathrm{~mL}$ was bioequivalent to MAOS $800 \mathrm{mg} / 20 \mathrm{~mL}$ under fed conditions; ${ }^{5}$ however, when PK parameters were analyzed under fasting conditions, MA-ES unexpectedly showed greater bioavailability than MAOS. Bioavailability, or the amount of drug available to provide a therapeutic response, is dependent on absorption. ${ }^{7}$ Since drug absorption and bioavailability under fasting conditions are particularly relevant to patients with cachexia, studies to characterize the PK profiles of MA-ES and MAOS were undertaken. This paper describes results from three studies evaluating the food effect on bioavailability of
MA-ES $625 \mathrm{mg} / 5 \mathrm{~mL}$ and MAOS $800 \mathrm{mg} / 20 \mathrm{~mL}$ in healthy individuals under fed and fasting conditions.

\section{Methods}

\section{Study I: Open-label, randomized, two-way crossover study of MA-ES $625 \mathrm{mg} / 5 \mathrm{~mL}$}

A prospective, randomized, open-label, two-way crossover study to evaluate the bioavailability of MA-ES under fed and fasting conditions was conducted in healthy male volunteers, 18 to 55 years of age, with no clinically significant medical histories (Figure 1).

Subjects were screened up to 28 days prior to receiving treatment. Following screening, subjects were randomized to receive a single dose of MA-ES $625 \mathrm{mg} / 5 \mathrm{~mL}$ after an overnight fast of at least 10 hours, or immediately after eating a standard, high-calorie, high-fat meal of 800 to 1000 calories consisting of 2 eggs fried in butter, 2 slices of toast with butter, 2 strips of bacon, $4 \mathrm{oz}$ of hash brown potatoes, and $8 \mathrm{oz}$ of whole milk. ${ }^{8}$ The study drug was administered orally with the standard $8 \mathrm{oz}$ of water. Following a 14-day washout period, subjects received a second single dose of MA-ES under the crossover (fed or fasting) condition.

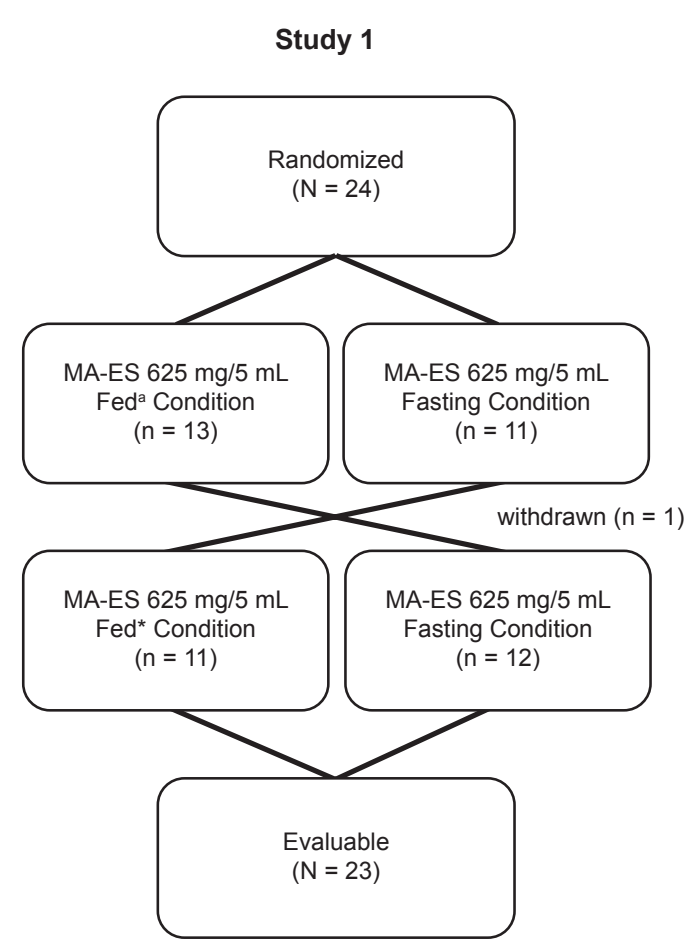

Study 2

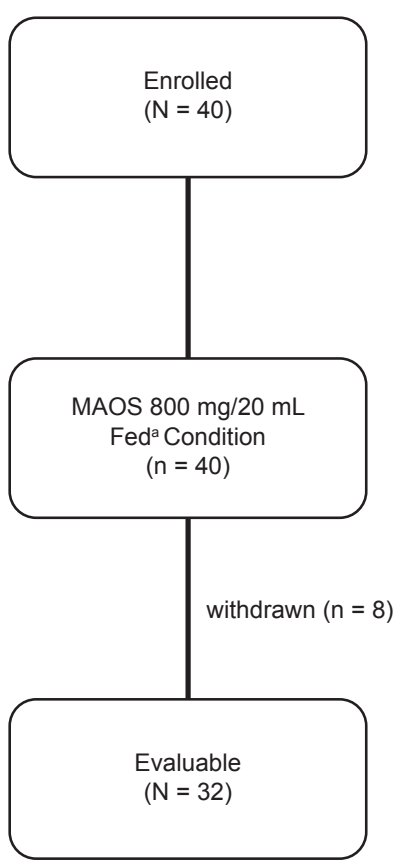

Study 3

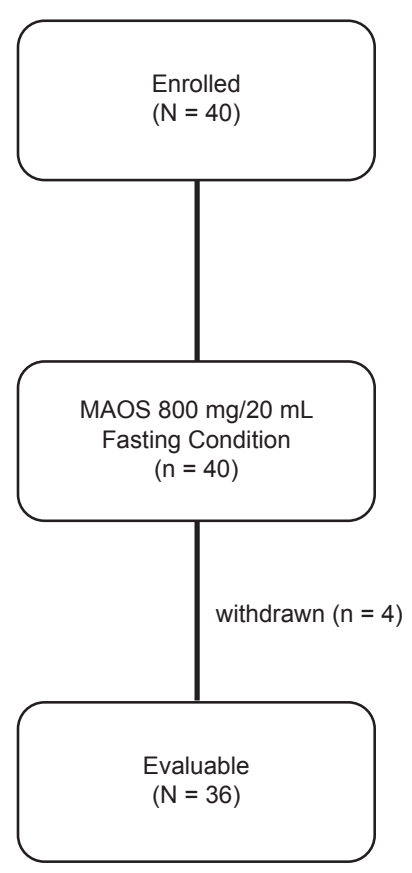

Figure I Flow diagrams for pharmacokinetic studies of a nanocrystal dispersion of megestrol acetate (MA-ES) $625 \mathrm{mg} / 5 \mathrm{~mL}$ and a micronized formulation of megestrol acetate oral suspension (MAOS) $800 \mathrm{mg} / 20 \mathrm{~mL}$ in fed and fasting subjects.

Note: ${ }^{a} 800$ to 1000 calories, $\sim 50 \%$ fat. 
During each treatment period, subjects remained at the study site for at least 10 hours pre-dose through 24 hours post-dose, after which they were discharged but returned at specified times for blood sample collection up to 120 hours post-dose. Plasma concentrations of megestrol acetate were quantified by a validated liquid chromatography, tandem mass spectrometric method. The lower limit of quantification was $2 \mathrm{ng} / \mathrm{mL}$.

Bioequiv (release 3.50) proprietary software (SFBC Anapharm, Sainte-Foy, Quebec, Canada) was used to calculate the following PK parameters: area under the plasma concentration-time curve (AUC) from time 0 to the time of the last non-zero concentration of the study drug $\left(\mathrm{AUC}_{0-\mathrm{t}}\right)$; $\mathrm{AUC}$ from time 0 to infinity $\left(\mathrm{AUC}_{0-\infty}\right)$; maximum observed plasma concentration $\left(\mathrm{C}_{\max }\right)$; time to $\mathrm{C}_{\max }\left(\mathrm{t}_{\max }\right)$; and elimination half-life $\left(\mathrm{t}_{1 / 2}\right)$. Descriptive statistics were tabulated by treatment for all PK parameters, as applicable. For $\mathrm{AUC}_{0-\mathrm{t}}, \mathrm{AUC}_{0-\infty}$, and $\mathrm{C}_{\max }$, analysis of variance (SAS General Linear Models procedure) was used to compare logarithmic-transformed (base) values from the fed and fasting treatments. This model includes sequence, subject within sequence, study period, and treatment as factors. The $90 \%$ confidence intervals (CI) were estimated for the ratio (fed/fasting) of least-squares means (LSM).

Vital signs, electrocardiograms (ECG), and clinical laboratory parameters (hematology, blood chemistry, and urinalysis) were monitored, and adverse events were recorded throughout the study.

\section{Studies 2 and 3: Open-label studies of MAOS $800 \mathrm{mg} / 20 \mathrm{~mL}$ in fed and fasting subjects $^{9}$ (Figure I)}

An open-label study to assess the bioavailability of MAOS under fed conditions (Study 2) was performed in healthy males at least 18 years of age, with no clinically significant medical histories. Subjects received a single, $800 \mathrm{mg} / 20 \mathrm{~mL}$ dose of MAOS within 30 minutes of consuming a standard high-calorie, high-fat meal as described previously. ${ }^{8}$ Blood samples were collected pre-dose, then sequentially for up to 96 hours post-dose. Plasma concentrations of megestrol acetate were measured by liquid chromatography with tandem mass spectrometry detection, and $\mathrm{PK}$ parameters $\left(\mathrm{C}_{\text {max }}\right.$, $\mathrm{t}_{\max }, \mathrm{AUC}_{0-\mathrm{t}}, \mathrm{AUC}_{0-\infty}$, and $\mathrm{t}_{1 / 2}$ ) were determined. Any adverse events reported throughout the study period were recorded.

An open-label study to assess the bioavailability of MAOS under fasting conditions (Study 3) was similarly performed in healthy males, at least 18 years of age, with no clinically significant medical histories. Subjects received a single, $800 \mathrm{mg} / 20 \mathrm{~mL}$ dose of MAOS after an overnight fast of at least 10 hours. The protocol for blood sampling and plasma concentration measurement was identical to the fed study, and the same PK parameters were evaluated. Adverse events reported throughout the study period were recorded.

All three studies received Institutional Review Board approval, and were conducted in accordance with Good Clinical Practice guidelines as required by the Declaration of Helsinki. All subjects provided written, informed consent.

\section{Results}

Study I: Open-label, randomized, two-way crossover study with MA-ES $625 \mathrm{mg} / 5 \mathrm{~mL}$

A total of 24 subjects were randomized to the study; the analysis population included 23 subjects. One subject who did not follow protocol and received treatment under the wrong condition was discontinued from the study. Megestrol acetate plasma concentrations were zero in all subjects prior to dosing in both study periods.

The PK parameters for MA-ES $625 \mathrm{mg} / 5 \mathrm{~mL}$ administered under fed and fasting conditions are shown in Table 1. $\mathrm{AUC}_{0-\infty}$ decreased from $16,268 \mathrm{ng} \cdot \mathrm{h} / \mathrm{mL}$ in the fed state to $12,095 \mathrm{ng} \cdot \mathrm{h} / \mathrm{mL}$ in the fasting state. The mean $\mathrm{C}_{\max }$ decreased from $1,618 \mathrm{ng} / \mathrm{mL}$ in the fed to $1,133 \mathrm{ng} / \mathrm{mL}$ in the fasting state. Absorption of MA-ES based on AUC and $\mathrm{C}_{\max }$ showed a decrease of $26 \%$ and $30 \%$, respectively, in the fasting compared with the fed state. The fed to fasting ratios ( $90 \% \mathrm{CI})$ of least-squares means for $\mathrm{AUC}_{0-t}, \mathrm{AUC}_{0-\infty}$, and $\mathrm{C}_{\max }$, were 1.36 (1.26 to 1.47 ), 1.36 (1.26 to 1.47 ), and 1.48 (1.28 to 1.71), respectively, indicating that consumption of a high-fat meal increased the rate and extent of absorption of MA-ES. Figure 2 shows the profile for mean plasma concentration over time for MA-ES administered under fed or fasting conditions.

All 24 subjects were included in the safety population. The drug was well tolerated under both fed and fasting conditions. There were no deaths, serious adverse events or other clinically relevant adverse events. Table 2 shows the 9 treatment-emergent adverse events that were reported. Each adverse event was reported once, except for increased blood pressure, which was reported in 2 subjects. All adverse events were mild to moderate in intensity, except for an incident of severe vomiting reported by 1 patient during the fed condition of the crossover treatment. The frequency and severity of adverse events were similar under fed and fasting conditions, and the majority of adverse events had resolved spontaneously by the end of the study. Changes in ECGs, 
Table I Mean (SD) pharmacokinetic parameters for a nanocrystal dispersion of megestrol acetate (MA-ES) $625 \mathrm{mg} / 5 \mathrm{~mL}$ and a micronized formulation of megestrol acetate oral suspension (MAOS) $800 \mathrm{mg} / 20 \mathrm{~mL}$ administered in a fed or fasting state

\begin{tabular}{|c|c|c|c|c|}
\hline \multirow[t]{3}{*}{ Parameter } & \multirow{2}{*}{\multicolumn{2}{|c|}{$\frac{\text { MA-ES } 625 \mathrm{mg} / 5 \mathrm{~mL}}{\text { Study I }(\mathrm{N}=23)}$}} & \multicolumn{2}{|c|}{ MAOS $800 \mathrm{mg} / 20 \mathrm{~mL}$} \\
\hline & & & \multirow{2}{*}{$\begin{array}{l}\text { Study } 2(\mathbf{N}=32) \\
\text { Fed }\end{array}$} & \multirow{2}{*}{$\begin{array}{l}\text { Study } 3(\mathbf{N}=36) \\
\text { Fasting }\end{array}$} \\
\hline & Fed & Fasting & & \\
\hline $\mathrm{AUC}_{0-\mathrm{t}}(\mathrm{ng} \cdot \mathrm{h} / \mathrm{mL})$ & I5,287 $(4,646)$ & II,30I $(3,583)$ & $16,757(4,670)$ & 7,0 II $(4,704)$ \\
\hline $\mathrm{AUC}_{0-\infty}(\mathrm{ng} \cdot \mathrm{h} / \mathrm{mL})$ & $16,268(5,174)$ & I2,095 (4,III) & $18,625(5,907)$ & $8,942(8,934)$ \\
\hline $\mathrm{C}_{\max }(\mathrm{ng} / \mathrm{mL})$ & $1,618(438)$ & I, I 33 (429) & $\mathrm{I}, 364(387)$ & $187(107)$ \\
\hline $\mathrm{t}_{\text {max }}(\mathrm{h})$ & $2.91(1.88)$ & $1.72(1.42)$ & $3.85(0.89)$ & $5.89(6.32)$ \\
\hline$t_{1 / 2}(h)$ & 39.75 (10.79) & $33.68(9.02)$ & $32.84(9.00)$ & $31.38(18.74)$ \\
\hline
\end{tabular}

Abbreviations: $A \cup C$, area under the curve; $C_{\max }$, maximum plasma concentration; $S D$, standard deviation; $t_{\max }$, time to maximum concentration; $t_{1 / 2}$, half-life.

clinical laboratory values, and vital signs were unremarkable and not considered related to therapy.

\section{Studies 2 and 3: Open-label studies of MAOS $800 \mathrm{mg} / 20 \mathrm{~mL}$ in fed and fasting subjects}

In study 2, 40 healthy volunteers were enrolled to evaluate MAOS bioavailability under fed conditions. Six subjects had protocol deviations and withdrew prior to study completion. One subject withdrew due to clinically significant hematology results, and another subject withdrew due to diarrhea. A total of 32 subjects provided evaluable data. Study 3 also enrolled 40 healthy male subjects, who were evaluated for MAOS bioavailability under fasting conditions. Four subjects were not included in the statistical analysis due to protocol deviations resulting in 36 subjects with evaluable data.
The PK parameters for an $800 \mathrm{mg} / 20 \mathrm{~mL}$ dose of MAOS given under fed or fasting conditions are summarized in Table 1. In the fed state, $\mathrm{AUC}_{0-\infty}$ was $18,625 \mathrm{ng} \cdot \mathrm{h} / \mathrm{L}$ and the mean $\mathrm{C}_{\max }$ was $1,364 \mathrm{ng} / \mathrm{mL}$. In the fasting state, $\mathrm{AUC}_{0-\infty}$ only reached 8,942 $\mathrm{ng} \cdot \mathrm{h} / \mathrm{L}$ with a $\mathrm{C}_{\max }$ of $187 \mathrm{ng} / \mathrm{mL}$. Relative to the fed state, $\mathrm{AUC}_{0-\infty}$ and $\mathrm{C}_{\max }$ were decreased by $52 \%$ and $86 \%$, respectively, in the fasting state. The mean plasma concentration-time profiles for MAOS after administration of a high-fat meal and during a fasting state are shown in Figure 3.

For the 32 subjects included in the safety population of the study conducted under fed conditions, adverse events were generally mild or moderate in severity. There was 1 unrelated severe adverse event of vomiting, 13 days post-dose. No serious adverse events were reported, and all adverse events were considered unlikely to be related to the study medication. For the 36 subjects included in the safety population of the study conducted under fasting conditions,

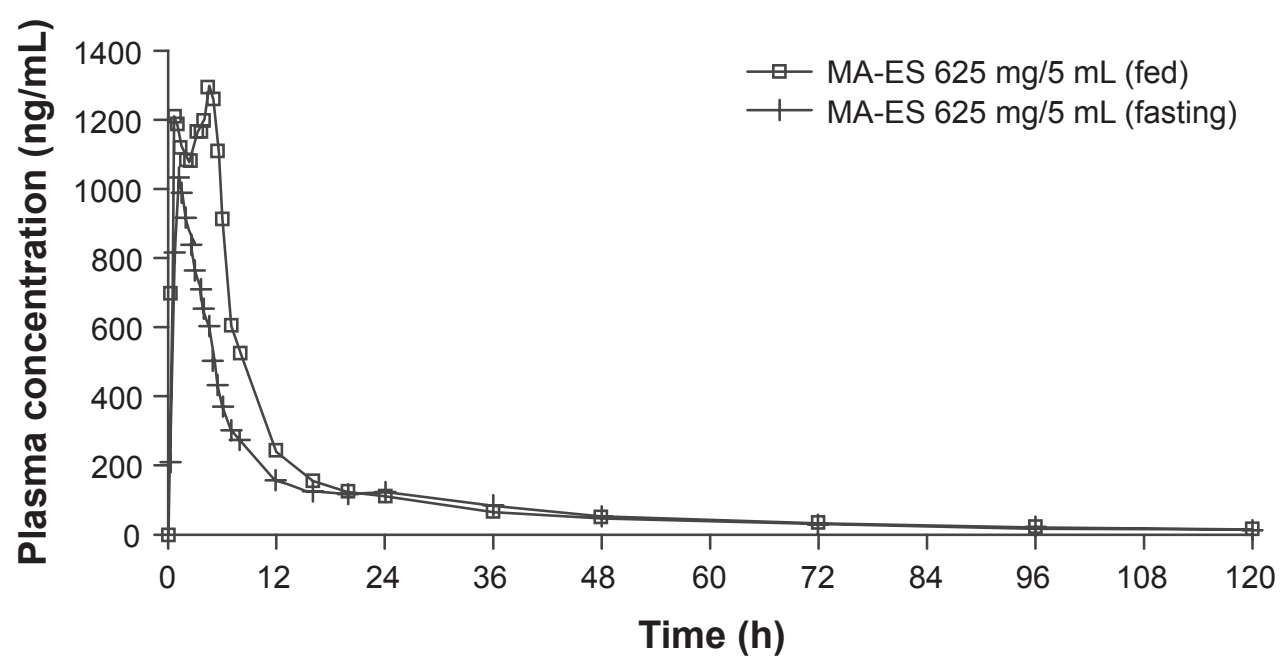

Figure 2 Mean plasma concentration profile for a nanocrystal dispersion of megestrol acetate (MA-ES) $625 \mathrm{mg} / 5 \mathrm{~mL}$ in fed and fasting states ( $\mathrm{N}=23$ ). Data from Study I.

Note: aean plasma concentration across all subjects at each time point. 
Table 2 Incidence of adverse events following a single dose of a nanocrystal dispersion of megestrol acetate (MA-ES) $625 \mathrm{mg} / 5 \mathrm{~mL}$ (Study I)

\begin{tabular}{lll}
\hline & $\begin{array}{l}\text { Fed (N = 24) } \\
\mathbf{n}(\%)\end{array}$ & $\begin{array}{l}\text { Fasting (N = 23) } \\
\mathbf{n}(\%)\end{array}$ \\
\hline Patients with at least one AE & $3(12.5 \%)$ & $4(17.4 \%)$ \\
Blood glucose increased & $\mathrm{I}(4.2 \%)$ & $0(0.0)$ \\
Skin exfoliation & $\mathrm{I}(4.2 \%)$ & $0(0.0)$ \\
Vomiting & $\mathrm{I}(4.2 \%)$ & $0(0.0)$ \\
Blood pressure increased & $0(0.0)$ & $2(8.7 \%)$ \\
Headache & $0(0.0)$ & $\mathrm{I}(4.3 \%)$ \\
Heart rate increased & $0(0.0)$ & $\mathrm{I}(4.3 \%)$ \\
Palpitations & $0(0.0)$ & $\mathrm{I}(4.3 \%)$ \\
Protein urine & $0(0.0)$ & $\mathrm{I}(4.3 \%)$ \\
\hline
\end{tabular}

adverse events were mild or moderate in severity. No serious, severe, or significant adverse events were reported.

\section{Food effect on bioavailability of MA-ES and MAOS}

As shown in Figure 4, single doses of MA-ES $625 \mathrm{mg} / 5 \mathrm{~mL}$ and MAOS $800 \mathrm{mg} / 20 \mathrm{~mL}$ have comparable bioavailability under fed conditions, but under fasting conditions the bioavailability of MA-ES is greater than that of MAOS.

\section{Discussion}

Bioequivalence of MA-ES $625 \mathrm{mg} / 5 \mathrm{~mL}$ to MAOS $800 \mathrm{mg} / 20 \mathrm{~mL}$ is seen under fed conditions; however, the bioavailability of a poorly water soluble ${ }^{10}$ lipophilic drug, such as megestrol acetate,,${ }^{11}$ is greatly impacted under fasting conditions.

Drugs with poor water-solubility are frequently associated with highly variable absorption based upon food intake. ${ }^{10}$ The enhanced bioavailability of MAOS when taken with a high-fat meal is predictable, as the lipophilic drug dissolves readily in the fat content of food. In the fasting state, MAOS demonstrates poor bioavailability, probably due to its poor water solubility, which contributes to reduced dissolution. The change in the absorption profile of MAOS between fed and fasting states had not been characterized when the drug was initially approved for marketing in 1993.

Solubility, and thus absorption and bioavailability, of lipophilic drug molecules can be improved with a reduction in particle size to submicron levels. ${ }^{12}$ To improve the solubility of megestrol acetate, nanocrystal technology was applied to the original formulation to reduce the drug particle size to 80 to $400 \mathrm{~nm}$ in diameter (up to 50 times smaller than the micronized particles in MAOS), thus increasing the total surface area of drug particles and improving dissolution of MA-ES. When the PK data for MA-ES was compared to that of MAOS, the difference between drug absorption of the two formulations under fasting conditions became apparent.

Results from the current studies demonstrate that $\mathrm{C}_{\max }$ and total absorption $\left(\mathrm{AUC}_{0-\infty}\right)$ of MAOS are markedly reduced (by $86 \%$ and $52 \%$, respectively) in fasting

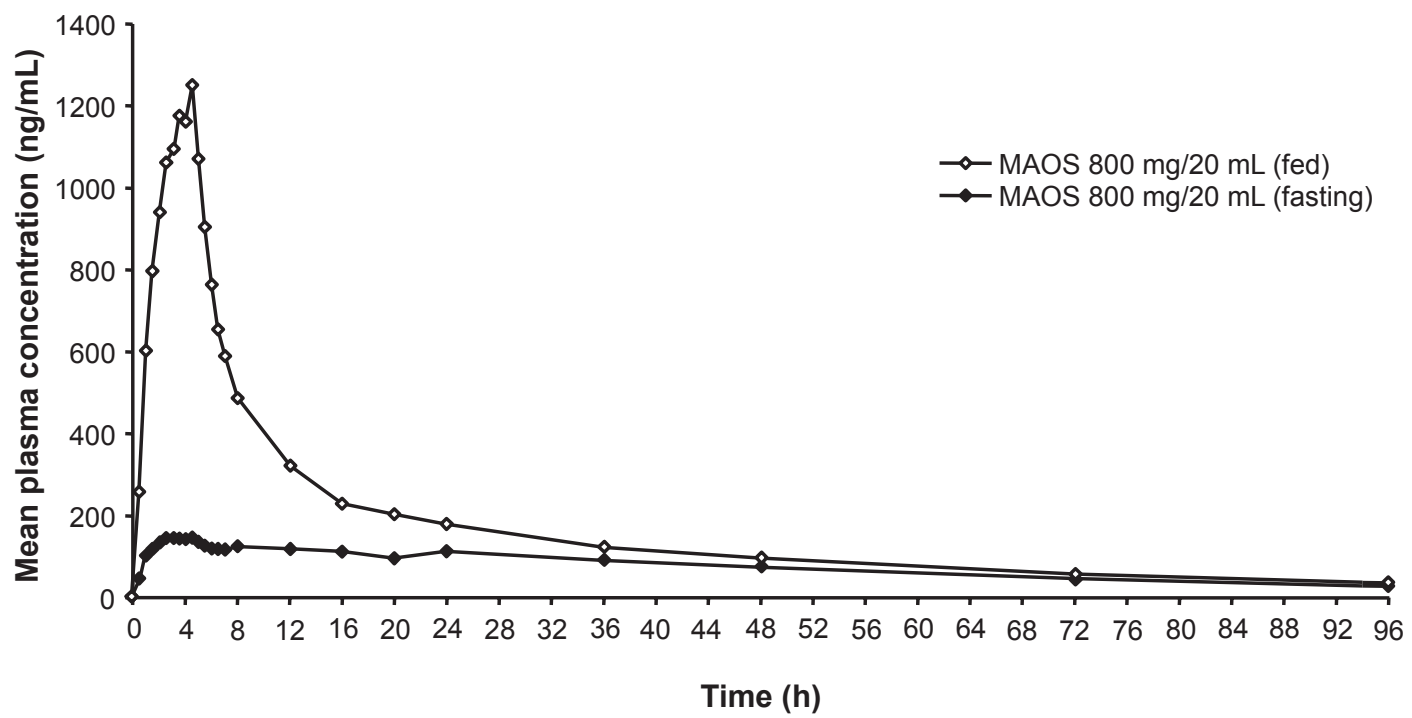

Figure 3 Mean plasma concentration profile ${ }^{a}$ for a micronized formulation of megestrol acetate oral suspension (MAOS) $800 \mathrm{mg} / 20 \mathrm{~mL}$ in fed and fasting states. Data from Study 2, MAOS in fed $(\mathrm{N}=32)$ subjects, and Study 3, MAOS in fasting $(\mathrm{N}=36)$ subjects.

Note: a Mean plasma concentration across all subjects at each time point. 


\section{Fed condition ${ }^{a, b}$}

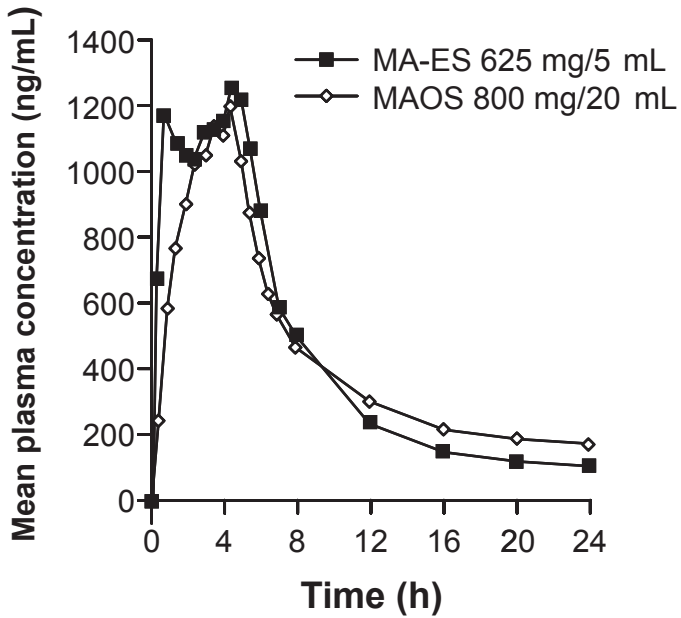

\section{Fasting condition ${ }^{c}$}

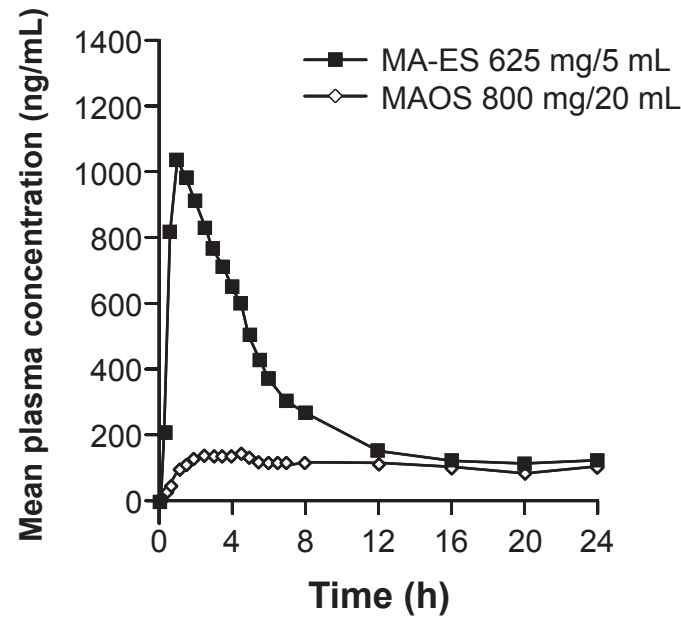

Figure 4 Food effect differences between a nanocrystal dispersion of megestrol acetate (MA-ES) $625 \mathrm{mg} / 5 \mathrm{~mL}$ and a micronized formulation of megestrol acetate oral suspension (MAOS) $800 \mathrm{mg} / 20 \mathrm{~mL}$.

a 800 to 1000 calories, $\sim 50 \%$ fat.

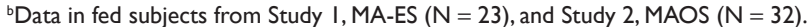

'Data in fasting subjects from Study I, MA-ES $(\mathrm{N}=23)$, and Study 3, MAOS $(\mathrm{N}=36)$.

versus fed subjects. Since cachectic patients can have minimal appetite, and are often in the fasted state, the poor bioavailability of MAOS in this state may be a significant impediment. Graham et al report in their 21-day study of AIDS patients with cachexia that there is a significant correlation between sustained plasma concentrations of MAOS above a threshold of $300 \mathrm{ng} / \mathrm{mL}$ and weight gain. ${ }^{13}$ Patients in the study were administered MAOS $800 \mathrm{mg} / 20 \mathrm{~mL}$, once daily, prior to breakfast. We report a $\mathrm{C}_{\max }$ value of $187 \mathrm{ng} / \mathrm{mL}$ for MAOS in the fasting state, which is below the $300 \mathrm{ng} / \mathrm{mL}$ threshold suggested for weight gain to occur.

$\mathrm{C}_{\max }$ and total absorption of MA-ES in fasting versus fed subjects are reduced by much smaller margins $(30 \%$ and $26 \%$, respectively). Since absorption of MA-ES is less profoundly affected by the presence or absence of food, this formulation may offer potential clinical benefit for cachectic patients with impaired appetite and low caloric intake. HIV-positive patients ( $n=63$ ) with $\geq 10 \%$ unintended weight loss were randomized to once daily treatment with MA-ES $575 \mathrm{mg} / 5 \mathrm{~mL}$ or MAOS $800 \mathrm{mg} / 20 \mathrm{~mL}$ for 12 weeks. ${ }^{14}$ Although MA-ES $575 \mathrm{mg} / 5 \mathrm{~mL}$ is not an FDA-approved dose, it is formulated using nanocrystal technology. Patients receiving MA-ES $575 \mathrm{mg} / 5 \mathrm{~mL}$ showed statistically significant weight gain from baseline as early as week 1 . At the end of 12 weeks patients gained an average of $10 \%$ (11.9 lbs; $5.4 \mathrm{~kg}$ ) of their baseline weight, which was statistically significant $(P<0.05)$. In addition, weight gain from baseline during the study was statistically significant at several time points. Patients receiving MAOS did not show weight gain until week 2. At the end of 12 weeks, patients gained an average of $6 \%(7.7 \mathrm{lbs} ; 3.5 \mathrm{~kg})$ of their baseline weight, but weight gain was not statistically significant at any time point from baseline.

At study end, MA-ES $575 \mathrm{mg} / 5 \mathrm{~mL}$ patients did gain the $10 \%$ weight they had lost at baseline, and weight gain occurred more rapidly at each time point than for MA-OS. The difference in weight gain results between MA-ES $575 \mathrm{mg} / 5 \mathrm{~mL}$ and MA-OS may be due to the improved absorption of the MA-ES formulation in people who have not eaten, although this study was not controlled for food or caloric intake. Most studies evaluating orexigenic agents for treatment of unintended weight loss are 12 weeks in duration. ${ }^{15-18}$ The improved bioavailability of MA-ES may facilitate earlier weight gain, and potentially shorten treatment duration.

The MA-ES formulation is associated with other properties that may be important to patients or caregivers. Since the MA-ES formulation is more concentrated at $125 \mathrm{mg} / \mathrm{mL}$ than MAOS, which is $40 \mathrm{mg} / \mathrm{mL}$, the 
recommended dose of MA-ES is delivered in a smaller volume of $5 \mathrm{~mL}$ (1 teaspoonful), once daily; whereas, the recommended dose of MAOS is $20 \mathrm{~mL}$ (4 teaspoonsful), once daily. ${ }^{19}$ The reduction in megestrol acetate particle size in the MA-ES formulation also resulted in a suspension that is much less viscous than MAOS (10 centipoise versus 163 centipoise, respectively [data on file, Par Pharmaceutical, Inc., Spring Valley, New York, USA]). These factors may make MA-ES more palatable for patients who lack appetite and/or may have difficulty swallowing.

Although MAOS and MA-ES contain the same active ingredient, they are not considered therapeutic equivalents ${ }^{20}$ because of the differences in concentration and fasting bioavailability between each drug.

The PK profile for MAOS under fed and fasted conditions (Study 2 and Study 3) was needed for the MA-ES New Drug Application submitted to the FDA. FDA approval was based on bioequivalence of MA-ES to MAOS under fed conditions. Subsequently, Study 1 was conducted to further characterize the food-effect bioavailability of MA-ES. Since the PK profile for MAOS was already established, the results were evaluated relative to the PK profile of MA-ES from Study 1. Although these 3 PK studies described in the current report were conducted in a similar manner among healthy male subjects, the potential for differences between the study populations, assays, and sampling techniques cannot be discounted. Thus, any comparison of data across studies should be undertaken carefully. These studies are also limited by the absence of female subjects from the study populations.

A further limitation of these studies is that PK parameters in healthy volunteers may not be generalizable to cachectic patients, who suffer from underlying disease, take concomitant medications, and may be elderly. Studies evaluating food effects and the effect of variable caloric intake on the bioavailability of MA-ES and MAOS, and correlation with clinical improvement in patients with cachexia would be of interest.

\section{Conclusions}

Food intake has the potential to affect drug absorption and bioavailability. This is a particularly important consideration when treating patients with cachexia or UWL because they often have low caloric intake. MA-ES is an improved formulation that is more readily absorbed and has improved bioavailability in the fasting state as compared to the original megestrol acetate oral suspension.

\section{Acknowledgments and disclosures}

Editorial assistance was provided by BioScience Communications and Prescott Medical Communications Group.

These studies were conducted by qualified investigators at SFBC Anapharm, Montréal, Canada, under the sponsorship of PAR Pharmaceutical, Inc., Woodcliff Lake, NJ.

\section{References}

1. Thomas DR, Ashmen W, Morley JE, Evans WJ. Nutritional management in long-term care: development of a clinical guideline. Council for Nutritional Strategies in Long-Term Care. J Gerontol A Biol Sci Med Sci. 2000;55(12):M725-M734.

2. Kuczmarski MF, Weddle DO. Position paper of the American Dietetic Association: nutrition across the spectrum of aging. J Am Diet Assoc. 2005;105(4):616-633.

3. Evans WJ, Morley JE, Argiles J, et al. Cachexia: a new definition. Clin Nutr. 2008;27(6):793-799.

4. Morley JE, Thomas DR, Wilson MM. Cachexia: pathophysiology and clinical relevance. Am J Clin Nutr. 2006;83(4):735-743.

5. Megace [package insert]. Princeton, NJ: Bristol-Myers Squibb Company; 2007.

6. Femia RA, Goyette RE. The science of megestrol acetate delivery: potential to improve outcomes in cachexia. Bio Drugs. 2005;19(3): 179-187.

7. Junghanns J-UAH, Müller RH. Nanocrystal technology, drug delivery and clinical applications. Int J Nanomedicine. 2008;3(3): 295-309.

8. Food Effect Working Group of the Biopharmaceutics Coordinating Committee, Office of Pharmaceutical Science. Guidance for industry: food-effect bioavailability and fed bioequivalence studies. http:// www.fda.gov/Drugs/GuidanceComplianceRegulatoryInformation/ Guidances/ucm064964.htm. Published December 2002. Accessed June 1, 2009.

9. Femia RA. Megestrol acetate concentrated suspension: results of dose-escalating studies under fed and fasting conditions. Poster presented at: 17th National HIV/AIDS Update Conference; April 2005; Oakland, CA.

10. Gennaro AR, Chase GD, Marderosian AD, Harvey SC, Hussar DA. Remington's Pharmaceutical Sciences. 18th ed. Easton, PA: Mack Publishing Company; 1990.

11. Lipp R, Funke A, Günther C. Compositions for use as penetration promoters in transdermal formulations for highly lipophilic active ingredients. http://www.freepatentsonline.com/EP1267884B1.html. Published 2004. Accessed June 4, 2009.

12. Hammond RB, Pencheva K, Roberts KJ, Auffret T. Quantifying solubility enhancement due to particle size reduction and crystal habit modification: case study of acetyl salicylic acid. J Pharm Sci. 2007;96(8):1967-1973.

13. Graham KK, Mikolich DJ, Fisher AE, Posner MR, Dudley MN. Pharmacologic evaluation of megestrol acetate oral suspension in cachectic AIDS patients. J Acquir Immune Defic Syndr. 1994;7(6): 580-586.

14. Wanke CGJ, Kristensen A, MacEarchern L. Safety and efficacy of two preparations of megestrol acetate in HIV-infected individuals with weight loss in Africa, India, and the United States. J Applied Res. 2007; 7:206-216.

15. Oster MH, Enders SR, Samuels SJ, et al. Megestrol acetate in patients with AIDS and cachexia. Ann Intern Med. 1994;121(6): 400-408.

16. Von Roenn JH, Armstrong D, Kotler DP, et al. Megestrol acetate in patients with AIDS-related cachexia. Ann Intern Med. 1994;121(6): 393-399. 
17. Grunfeld C, Kotler DP, Dobs A, Glesby M, Bhasin S. Oxandrolone in the treatment of HIV-associated weight loss in men: a randomized, double-blind, placebo-controlled study. J Acquir Immune Defic Syndr. 2006;41(3):304-314.

18. Timpone JG, Wright $\mathrm{D}, \mathrm{Li} \mathrm{N}$, et al. The safety and pharmacokinetics of single agent and combination therapy with megestrol acetate and dronabinol for the treatment of HIV-wasting syndrome. AIDS Res Hum Retroviruses. 1997;13(4):305-315.
19. Megace ES [package insert]. Spring Valley, NY: Par Pharmaceutical, Inc; 2008

20. Food and Drug Administration, Center for Drug Evaluation and Research. Orange Book: Approved Drug Products With Therapeutic Equivalence Evaluations. 29th ed. Rockville, MD. http://www. accessdata.fda.gov/scripts/cder/ob/default.cfm. Updated May 2009. Accessed June 2, 2009.

\section{Publish your work in this journal}

The International Journal of Nanomedicine is an international, peerreviewed journal focusing on the application of nanotechnology in diagnostics, therapeutics, and drug delivery systems throughout the biomedical field. This journal is indexed on PubMed Central, MedLine, CAS, SciSearch $\AA$, Current Contents ${ }^{\circledR} /$ Clinical Medicine,
Journal Citation Reports/Science Edition, EMBase, Scopus and the Elsevier Bibliographic databases. The manuscript management system is completely online and includes a very quick and fair peer-review system, which is all easy to use. Visit http://www.dovepress.com/ testimonials.php to read real quotes from published authors. 